\title{
PROPOSED METHODOLOGY FOR MEASUREMENT, SURVEY AND ASSESSMENT OF VERTICAL DEFORMATION OF STRUCTURES
}

Author(s):

Jonathan Ruiz-Jaramillo (Architectural Constructions Department, Higher School of Architecture, University of Malaga, Malaga, Spain)

Emilio Mascort-Albea (Institute of Architecture and Building Science, Building Structures and Field Engineering Department, Higher School of Architecture, University of Seville, Seville, Spain)

Antonio Jaramillo-Morilla (Institute of Architecture and Building Science, Building Structures and Field Engineering Department, Higher School of Architecture, University of Seville, Seville, Spain)

\section{Citation:}

Jonathan Ruiz-Jaramillo , Emilio Mascort-Albea , Antonio Jaramillo-Morilla , (2016) "Proposed methodology for measurement, survey and assessment of vertical deformation of structures", Structural Survey, Vol. 34 Iss: 3, pp.276 - 296

DOI: http://dx.doi.org/10.1108/SS-02-2016-0006

\section{ABSTRACT}

\section{Purpose}

Growing awareness of the importance of preserving the built environment has created an increasing demand for experts capable of performing building inspections to ensure a high level of preservation. Technical surveys include a set of procedures and tests that have become essential tools providing the necessary knowledge required for maintenance, preservation and improvement of buildings.

\section{Design/methodology/approach}

Within this set of inspection techniques, this paper presents a method developed to produce vertical deformation plans from the levelling data obtained from different floors of a building. It also explains how to perform accurate levelling and an outcome analysis to provide displacement maps. Thus, based upon obtained measurements, it is possible to achieve 2D contour maps and 3D surface mapping by means of specialized software that is typically used for cartographic and territorial analysis.

\section{Findings}


The developed methodology provides easier analysis of the deformation of buildings and structures. Consequently, the method produces relatively accurate outcomes that are sufficient to make a proper assessment that facilitates the diagnostic and decision-making process. The case studies analysed show the applicability and usefulness of the procedure.

\section{Originality/value}

This sustainable and non-destructive system is an essential instrument for providing valuable and useful information to the specialist. The 2D/3D graphical data displays enable easier analysis of survey results, also aiding comprehension of these results in the context of liability claims.

KEYWORDS: assessment, dilapidation, non-destructive testing, levelling, vertical deformation, survey.

\section{INTRODUCTION}

The growing demand for high-quality construction has led to an increasing awareness of the importance of maintaining and improving the built environment (Ma et al. 2012). In this context, to allow appropriate management of building maintenance, conservation and enhancement, there is a need for competent technicians who are capable of performing surveys and subsequently producing reports on the state of building preservation. The work of such experts is focused mainly on inspection, assessment and provision of technical advice about complex aspects related to building pathology, mostly those derived from constructive and structural processes. This information can be especially helpful in the resolution of legal claims.

The regulatory framework of a given country provides the necessary requirements that every building has to satisfy, and it is essential for the assessment and surveying of existing buildings that compliance with these regulations is verified. In addition, the conclusions reached by experts during inspection work and documented in technical reports must be verified by appropriate testing and further analysis of building damage. For this task, an extensive array of tools and instruments is available, among which non-destructive techniques should be emphasized as an essential tool for the analysis of the state of buildings. Such methods have proven potential for the characterization of building materials, for 
determination of their level of degradation and for evaluation of the processes related to the appearance of various building pathologies (Moropoulou et al. 2013). Nevertheless, the conclusions and the amount of data produced by these techniques are sometimes difficult to analyse and to communicate to the desired audience (Guerra-Santin \& Tweed Aidan 2015).

Several studies of building pathology in different European countries have shown that most damage is due to deformation or movement of the structural system (Harris 2011). Figure 1 (Avilés 2011) presents in detail the statistics of building pathology in Spain over the last 30 years. This dataset, developed by ASEMAS (an insurance company created in 1983 to cover the professional liability of architects in Spain), includes all buildings and structures built in 1983 or thereafter. The analysis reveals that more than $50 \%$ of damages claimed on buildings were caused by deformation of the structures or movement of the foundations. These problems are illustrated by the presence of fractures and cracks in structural and construction elements (Watt 2008).

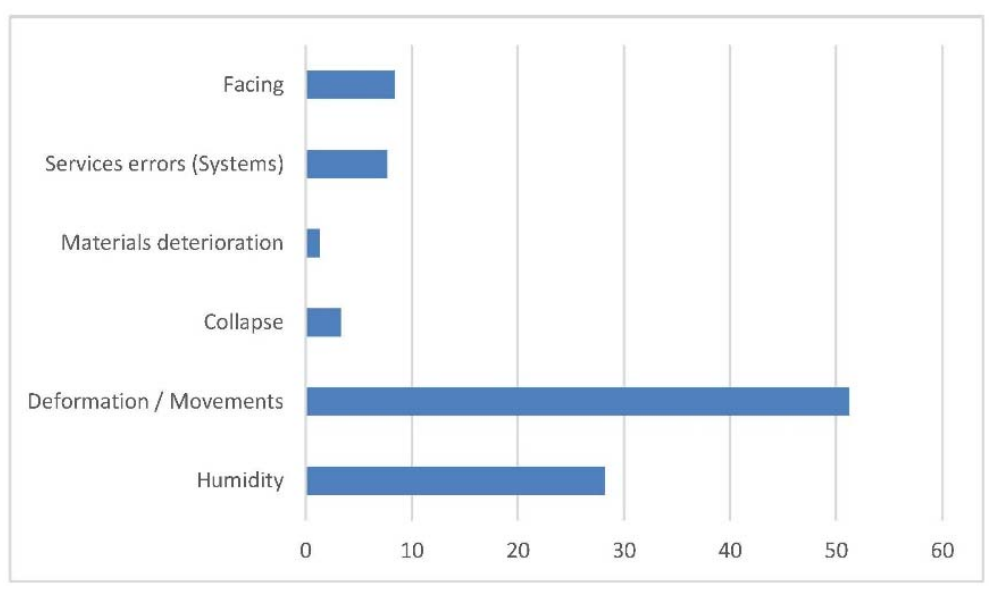

Figure 1. Main causes of building pathology in Spain since $1983(\%)$.

This analysis reveals the importance of establishing a diagnostic system based on data obtained from the measurement of deformation in structural elements. Specific knowledge about deformation and movement plays an important role in characterizing the pathology and degradation process of a building. Nowadays, it is possible to use a number of different procedures to obtain such data, such as topographic networks for three-dimensional (3D) control using total stations or geometric levelling. These may be combined with more complex procedures such as portable digital photogrammetric 
stations (DPS) or a terrestrial laser scanner (TLS) system (Fregonese et al. 2013). Specifically, the latter has become an essential tool when dealing with built-heritage buildings, providing very quickly a point cloud that creates a 3D model of the monument (Ioannidis \& Georgopoulos 2007; El-Tokhey et al. 2013). However, in general, these remote sensing technologies require the use of specialized equipment that is not readily available to most surveyors. This equipment is expensive to buy or rent and additional costs can be incurred because of the need to train or hire personnel capable of managing and modelling point cloud data. Additionally, the amount of data acquired by a TLS system makes it difficult to produce models. There are many software systems available to assist in this task, but these consume computing and time resources and again special equipment must be bought or hired. These techniques therefore have significant limitations, confining their application almost exclusively to architectural heritage inspection (Clarke \& Laefer 2013), where the available budgets and resources are both significantly higher.

Furthermore, even excluding the issues of cost and complexity, these techniques have other problems, mainly concerning the accuracy of the measurements they produce (Cuartero et al. 2010; Polo et al. 2012; Alkan \& Karsidag 2012). Changes in environmental conditions such as humidity and temperature (Durán-Dominguez et al. 2014), reflectivities of different colours and materials, the effects of angle of incidence (Berenyi et al. 2010), and problems due to close-range imaging (Patias et al. 2006) can generate possible dimensional errors in the model (Cosarca et al. 2009). Depending on these conditions, significant errors in the measurement of vertical displacements can occur, extending sometimes to an order of magnitude of more than $1 \mathrm{~cm}$, compared with direct measurements (Dumalski 2011). This highlights the importance of evaluation procedures that enable the calibration of laser scanners, especially during the development of high-precision surveys in architectural heritage sites. Typical tests such as deformation monitoring have to be checked through direct measurement procedures (Di Yajing \& Bai Chengjun 2011). 
This paper presents a low-cost, simple and effective methodology to facilitate vertical deformation measurements when monitoring buildings, avoiding the problems presented by other systems as described above. The measurements thus obtained are sufficiently accurate to provide a correct assessment of building pathology, thereby improving the diagnostic and decision-making process.

\section{MATERIALS AND METHODS}

\subsection{IN SITU LEVELLING PROCESS}

When performing a survey of a damaged building, the aim of the expert is to obtain the information necessary to obtain a detailed diagnosis (Josephson \& Hammarlund 1999). This has to be based on the analysis of data obtained mainly from specific tests performed in situ (Forcada et al. 2014). One of the most useful techniques in this context is interior levelling of the building under study. This method is usually applied during the construction process in order to control the gradient of drainage slopes on a roof or on the pavement or public space outside the building. Using the same procedure to measure the differences in level at several points of a slab floor, it is possible to obtain essential information related to vertical deflection or to differential settlement of the foundations. In this way, the method has the potential to provide information about the complexity of the state of a building through a simple analytical methodology (Russo 1980).

The purpose of the described procedure is thus to produce vertical deflection plans, which will allow diagnosis of structural damage. To accomplish this, the process is divided into three main phases:

1) On-site data collection: levelling of building floors.

2) Data analysis: tabulating the levels obtained by assigning to each node its $X Y$ coordinates with respect to a single reference system.

3) Obtaining vertical deflection data.

On-site collection of level values consists of performing a relative movement analysis focused on the horizontal planes of the building under study (Gubellini et al. 1986). The equipment required to do this is 
a self-levelling laser equipped with horizontal laser beams, a magnetically damped compensation system and an alarm to indicate when the laser is outside its self-levelling range. In addition, it is recommended that a vertical laser beam be used to verify the vertical position of the graduated scale or staff.

The monitoring is performed using rigid Invar staffs with barcode reading and a compact automatic laser device with an accuracy of $\pm 1 \mathrm{~mm} / 5 \mathrm{~m}$, a levelling range of $\pm 3^{\circ}$ and a working range without detector of $10 \mathrm{~m}$ (MEDID 2008). This laser is placed on a standard tripod to ensure the required stability, avoiding unexpected changes in laser height during the process.

\subsection{MEASUREMENT PROCESS}

The first step in the process is to place the self-levelling laser at a specific location within a room. It is best for it to be near the geometric centre of the room, which makes level measurements of the corners and points between them easier (Zotov 2003). To obtain the measurements, the centre column of the tripod is positioned at a certain height representing the horizontal plane of reference.

Once the laser has been positioned, the process proceeds, with representative room levels being taken; as a minimum, these should be the corners and the midpoints of the lines between them, especially for lengths up to 2.0-2.5 m. Using the rigid staff, vertical measures (Zlevels) with respect to the reference laser beam are taken at all these points (Figure 2a). The measurements may be made with respect to the upper face of a slab (floor) or its lower face (ceiling). In general, it is better to use the floor as a reference (Figure 2.b), although sometimes this is not possible because a horizontal level is unavailable as a result of the building's construction, as, for example, in the case of a drainage slope (on a roof or garage) or with floating flooring, which may lead to distortion of the results. Some deformations such as local floor sagging can also appear as structural problems, although they are nothing more than local material 'failure', namely simple wear of floorboards after many years of use, and are therefore not a major issue for the building overall. These largely diaphragmatic floors are notoriously flexible and should not be considered as part of the load path system of the structure for this type of analysis. In 
such cases, the best option is to carefully obtain the value from the slab underside (Figure 2.b), in order to reduce any loss of accuracy.

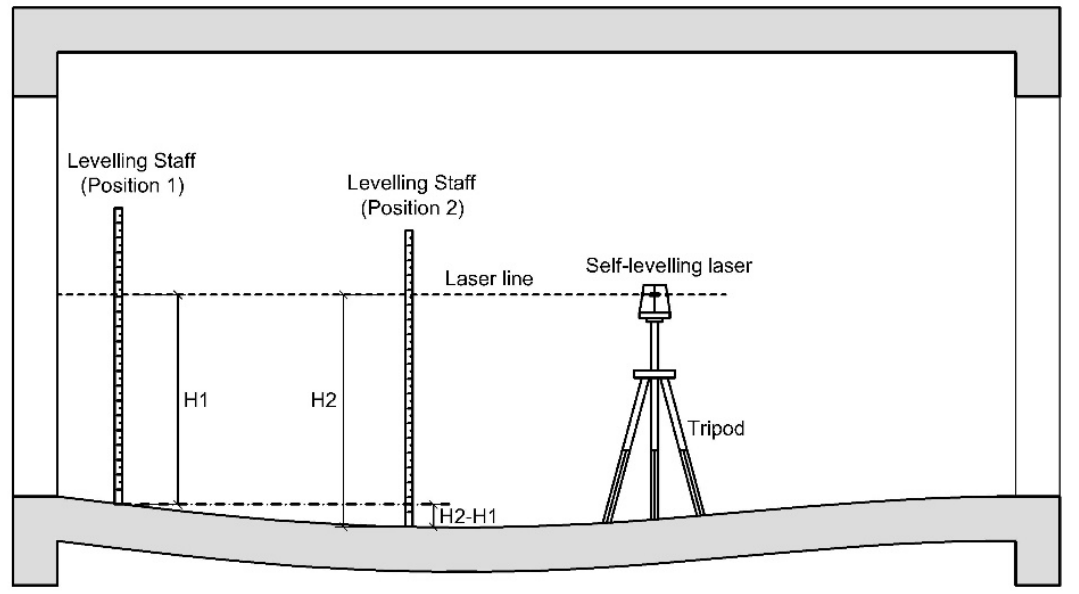

(a)

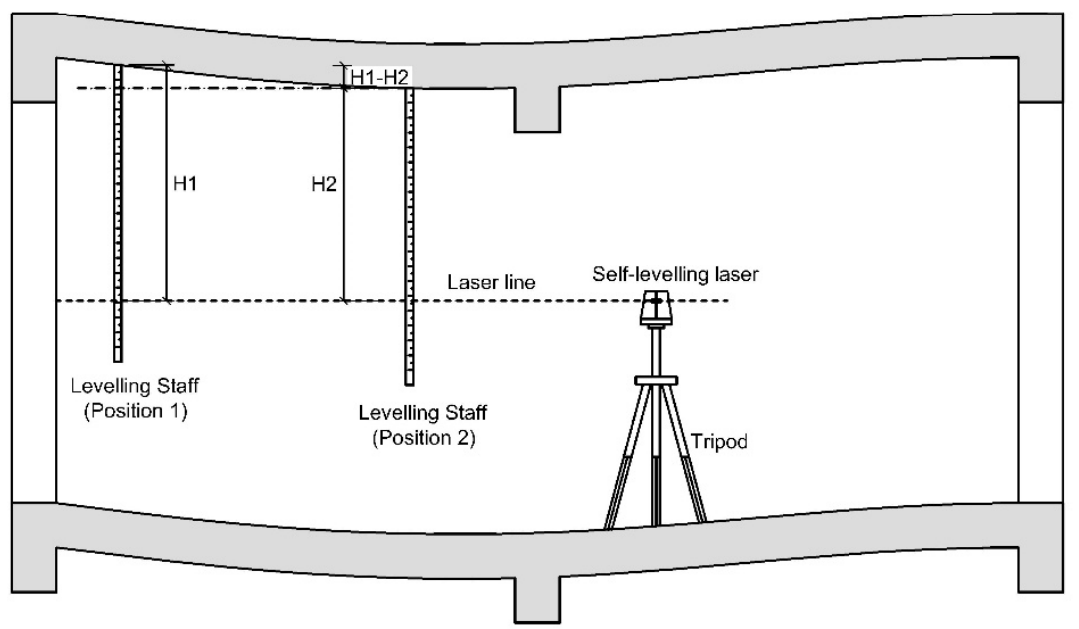

(b)

Figure 2. Schematic representation of levelling (a) the upper face and (b) the lower face of a slab.

To avoid these local problems, levelling should include several rooms or even an entire floor of a building. In these cases, it is important to keep the horizontal reference the same for each of the levelled rooms. When a common level is used for all the measured values, the results of the inspection work are more useful because this allows comparison of all the data for a given floor. In this context, partition walls cause difficulties because they introduce discontinuities in the laser beam between rooms. Additionally, possible differences in level between rooms can introduce changes in the height of the laser signal. Again, therefore, it is important to keep the same laser level throughout the entire survey. 
To aid this, a reflective adhesive survey target can be used or a narrow mark can be drawn (for example, using a pencil) at the position of the laser signal on one of the faces in the next room to provide a level before the tripod is moved. This facilitates adjustment of the laser height at its new position in the next room. The thickness of the laser line is no greater than $1 \mathrm{~mm}$ for a distance of $5 \mathrm{~m}$, so, to maintain accuracy, a target or mark should be placed at least every $5 \mathrm{~m}$ maximum (although this depends on the working range of the laser used). In addition, this technique helps in checking the accuracy of the levelling by verifying that the height of the laser has remained constant throughout the process. When this procedure is done correctly, the margin of error is less than $1 \mathrm{~mm}$, which is acceptable, taking into account the usual margin of error in construction work. The centre column of the tripod needs to have a proper height margin to allow for up-and-down movement, so that the height of the laser beam can be adjusted in each measured room to the reference plane created for the entire floor. The marks on the walls are also useful when further measurements are performed during later visits using the same reference as in the first survey, thus allowing comparison of results at different times.
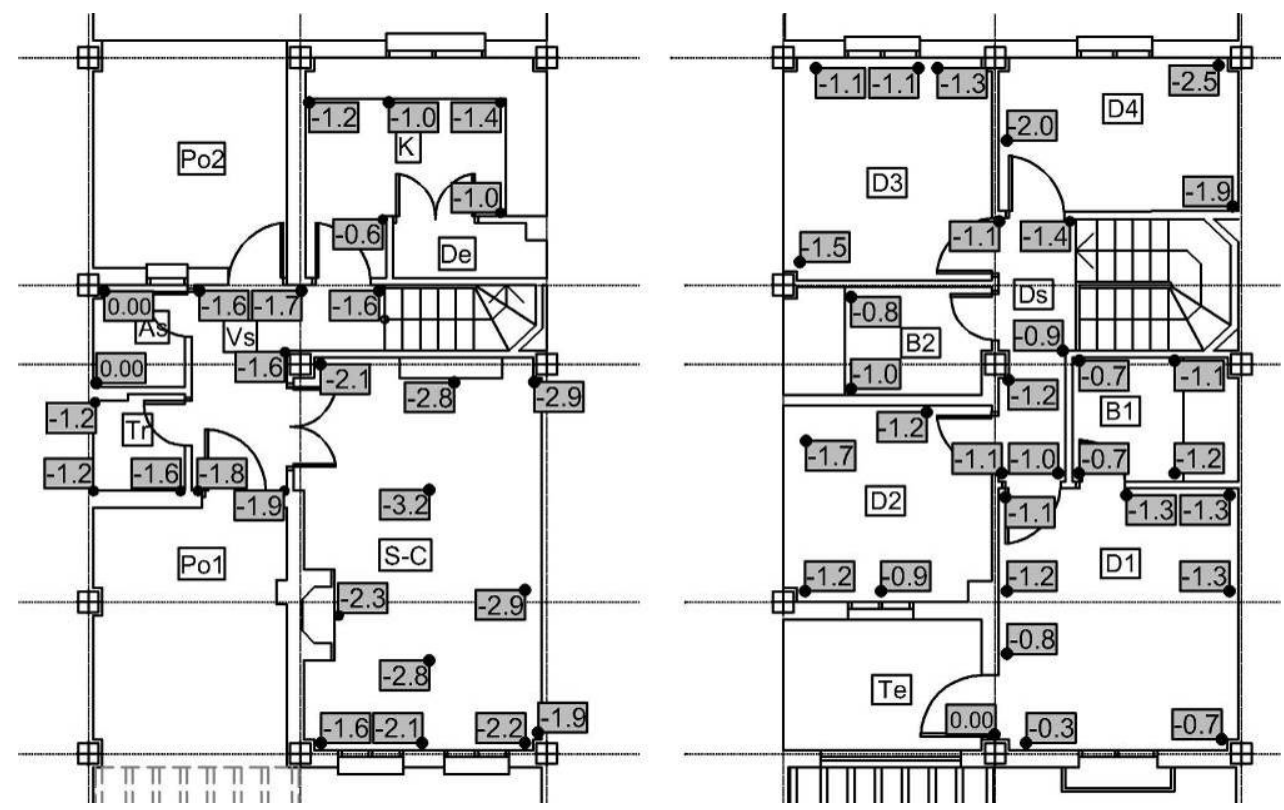

Figure 3. Levelling points and the associated Z-coordinates located on the ground and first floors of a building. 
Following this procedure, a $Z$ coordinate (level) is obtained at each point and this information is shown on the building floor plans (Figure 3). Displaying the information in this way allows a preliminary analysis to be performed and a diagnosis to be made regarding the vertical deformations and angular distortions of the building structure.

\section{THEORY AND CALCULATION}

\subsection{VERTICAL DEFORMATION PLANS}

The procedure described above establishes a vertical coordinate at each node of the horizontal floor area with respect to the reference laser beam projected on the wall faces. In addition, each $Z$ coordinate can be associated with $X-Y$ coordinates by placing the origin of the coordinate system at any point on the floor plan and taking it as a reference point. This means that from the origin $(0,0)$ it is possible to associate $X-Y$ coordinates with each node at which the $Z$ value has been measured. Once the three coordinates for each node have been obtained, it is possible to produce a graphical representation of structural vertical deformations. To do this, the obtained data are used to produce a spreadsheet in which the $X-Y-Z$ coordinates for each node are entered. Next, vertical deformation drawings are generated using specialized software for cartographic analysis (mapping). This process is illustrated in Figure 4. The software used here is Surfer (v. 11) by Golden Software. This allows contouring and surface modelling, making possible the analysis of surfaces, 2D contour mapping or/and 3D surface mapping. This software is normally used for territorial analysis (e.g. landscape and terrain, watershed, or bathymetric modelling), although it has not previously been used for building modelling.
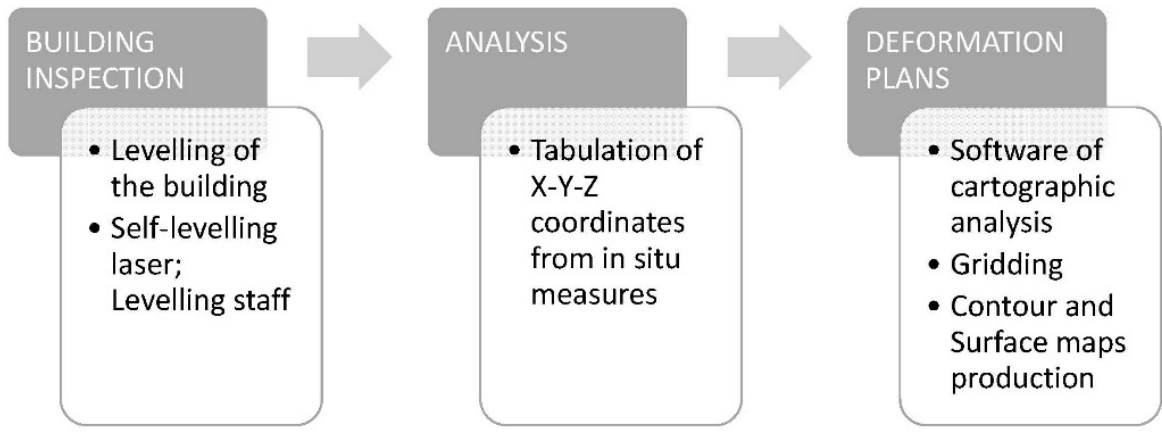
Figure 4. Proposed methodology to obtain vertical deformation plans.

Before the data are imported into the software, they need to be adequately prepared for the software to recognize them and hence improve the quality of the final result. To do this, a rectangular data matrix containing all the $X-Y$ coordinates associated with any particular node and its respective $Z$ value by columns is required (Upson et al. 1989). In addition, from this data matrix, it is possible to obtain the median of the $Z$ data, take this value as a new reference $(0,0)$ and then calculate modified $Z$ values associated with this new origin (Figure 5). This process allows a more comprehensive interpretation of the data, making the subsequent analysis easier.

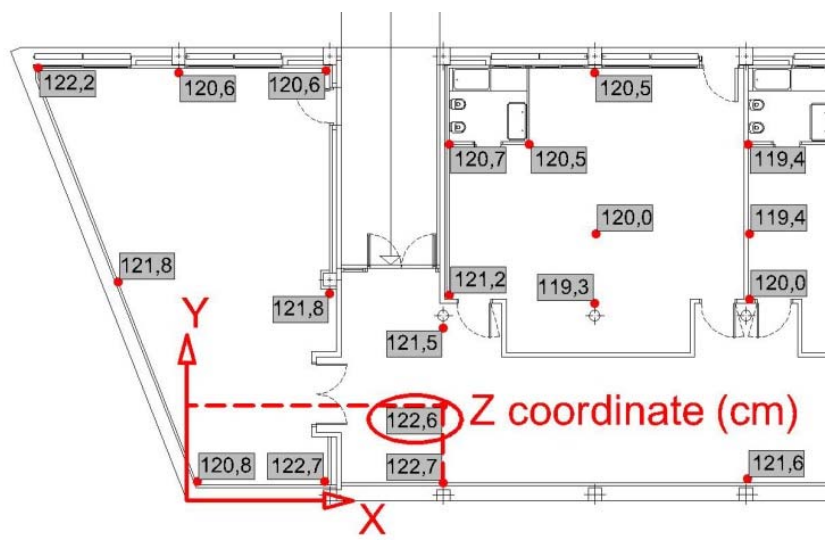

\begin{tabular}{|c|c|c|c|c|}
\hline$X(m)$ & $Y(m)$ & $\mathrm{Z}(\mathrm{m})$ & Median $(Z ; m)$ & Dif. $Z(m)$ \\
\hline 0,2834 & 0,5067 & 120,8 & \multirow{7}{*}{121,8} & 1,0 \\
\hline 3,6487 & 0,5067 & 122,7 & & $-0,9$ \\
\hline 6,7837 & 0,4767 & 122,7 & & $-0,9$ \\
\hline 6,7828 & 4,5691 & 121,5 & & 0,3 \\
\hline 3,7832 & 5,4832 & 121,8 & & 0,0 \\
\hline$-1,8192$ & 5,7967 & 121,8 & & 0,0 \\
\hline$-3,9218$ & 11,4550 & 122,2 & & $-0,4$ \\
\hline
\end{tabular}

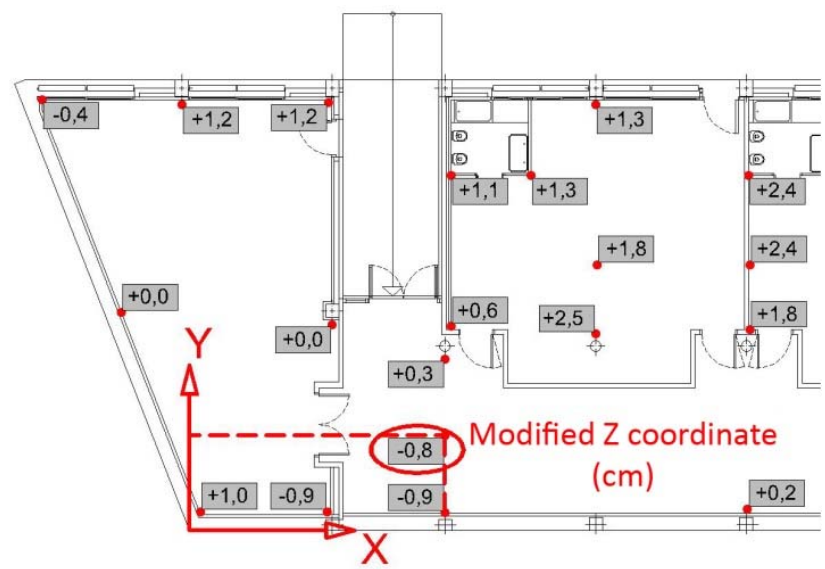

Figure 5. $X-Y-Z$ data array prepared before application of the cartographic analysis software. 
Organizing the data in this way involves the generation of a discontinuous 3D grid in which the points are located at irregular intervals. This means that there is no regular pattern extending over the entire measured floor. In addition, it is not possible to level an infinite number of points, so there will always be areas devoid of data. The software can use this information to create a regular grid linking each $Z$ value to any coordinate of the new grid using an interpolation method with respect to the original array (Bourges et al. 2012).

The software user has to select a gridding method to convert the data matrix from its situ inspection form into a regular grid. A number of methods are available to produce a regularly spaced rectangular array of $Z$ values from the data collected during the survey. The interpolation procedure is controlled by grid method parameters Among these gridding methods, the most relevant for the present purpose are inverse distance to a power, Kriging, minimum curvature, the modified Shepard method, natural neighbour, nearest neighbour, polynomial regression, radial basis function, and triangulation with linear interpolation. The differences between them lie in the mathematical algorithms used to compute the different heights during grid node interpolation. The main objective is to define the regular grid used by the software to generate the contours connecting points of equal elevation. Each method produces a different data representation; therefore, one of the key issues to be resolved is the selection of the gridding method. It is essential to make a good selection, otherwise the results obtained and therefore the diagnosis of the pathology will not be correct (Smith \& Ferris 2010). In general, the procedure for levelling interior spaces in a building that is mostly regular produces a homogeneous data set. Among the abovementioned methods, two stand out: Kriging and the radial basis function method. Kriging is useful for analysing most data sets mainly because it employs a linear variogram procedure. Hence, it is possible to obtain a balanced grid to generate an optimal contour map. Its main disadvantage is its slowness in acquiring the grid from analysis of a large data set. Meanwhile, the radial basis function method exhibits greater flexibility in data analysis and is able to generate a fairly regular meshing. Consequently, this method generates the best global interpretations for most data sets, producing final 
results similar to those of Kriging (Yan et al. 2004). These methods, together with the other gridding methods mentioned above, have been tested on several case studies using different data sets and it has been verified that those providing the best data interpretation are indeed Kriging and the radial basis function method. The other methods typically generate unsuitable results, causing, for example, the bull's-eye effect (Reynolds 2011).

During the grid definition process, the grid density and limits are key parameters to be taken into consideration by the user. The minimum and maximum $X$ and $Y$ coordinates of the initial array define the grid limits. Usually, these are related to the dimensions of the studied floor. Conversely, the grid density is usually defined by the number of columns and rows in the grid relative to the final number of nodes. Higher grid density improves the accuracy of the map, but it also increases the gridding and drawing times (Anon 2012).

Once a regular grid has been generated, the mapping software easily displays a 2D contouring map or 3D surface modelling, delivering global information about the area concerned. In addition, it is possible to obtain sections that directly show the deformation of the levelled surface on the main axis of the structure.

\section{RESULTS}

This approach to building inspection enables the construction of vertical deformation plans from floor levelling data. These maps allow verification of movement, deformation and level differences in the levelled area. They facilitate data analysis and increase the quality of the results obtained. As shown above, the method can be easily applied to the assessment of interior conditions, helping to quantify accurately (with a precision of $\pm 1 \mathrm{~mm}$ ) essential information about structural movements in a short time, thus simplifying the diagnostic process. Slab deflection, angular distortion between given points of a structure and vertical displacement with respect to foundations are easily revealed. With regard to the assessment of exterior conditions, it is possible to obtain information related to terrain movement and settlement, such as wall leanings. In the context of visual inspection of cracking when determining 
the condition of an entire building (Clarke \& Laefer 2013), it is sometimes necessary to have a larger set of data regarding the root cause of damage related to movement or deformation of construction or structural elements. Furthermore, it is possible to perform several data collections at different times. One measurement allows comparison of the results obtained with the non-deformed initial state of a building, allowing estimation of deflections of beams or slabs. Conversely, by comparing two or more data samples, it is possible to obtain details on relative movements of a building and thereby determine whether a pathological process is still active, as well as the degree of damage. This enables investigation of the existence of long-term movements after the passage of a certain amount of time. Compared with other approaches, the one described here is also very efficient in terms of time. The procedure takes about $1.5 \mathrm{~min} / \mathrm{m}^{2}$ of total built surface space, including both the inspection process and the office work needed to obtain the graphical deformation maps, indicating that this approach is more efficient than others such as photogrammetry and TLS (Grussenmeyer et al. 2008).

\section{DISCUSSION. CASE STUDIES}

The method described above has been used in multiple building inspections, with the results revealing its usefulness during the analysis process and its key role in diagnosis. In addition, this approach helps to justify proposed restoration measures within the design process (Camarda et al. 2010). Its efficiency has been proved during the analysis and diagnosis of symptoms that have caused damage in the case studies described below. The information obtained from vertical deformation maps has helped to clarify the origin of such damage. Additionally, in each case, it was possible to resolve the critical issue regarding whether or not the structure was still moving by performing various measurements at several visits. The number of such measurements required depends on the significance of the damage and its evolution over time. This dictates the nature and order of intervention, allowing selection of the most appropriate restoration measures and therefore optimization of the work budget (Fregonese et al. 2013). 


\subsection{SINGLE-FAMILY HOME IN SEVILLE}

The damage suffered by the single-family house in this study was mainly revealed by cracks in both exterior and interior walls (Figure 6) (Jaramillo-Morilla \& Pérez-Murillo 2011).

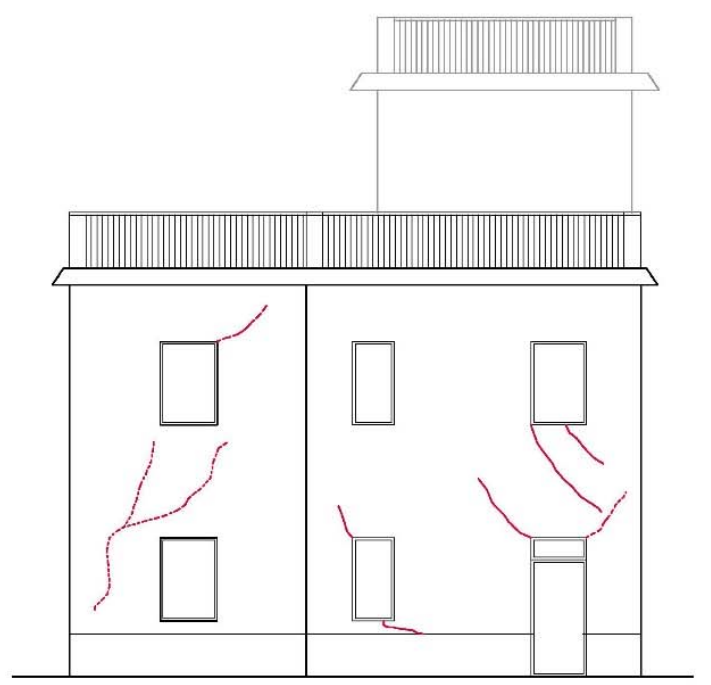

CRACKS IN THE EAST FAÇADE

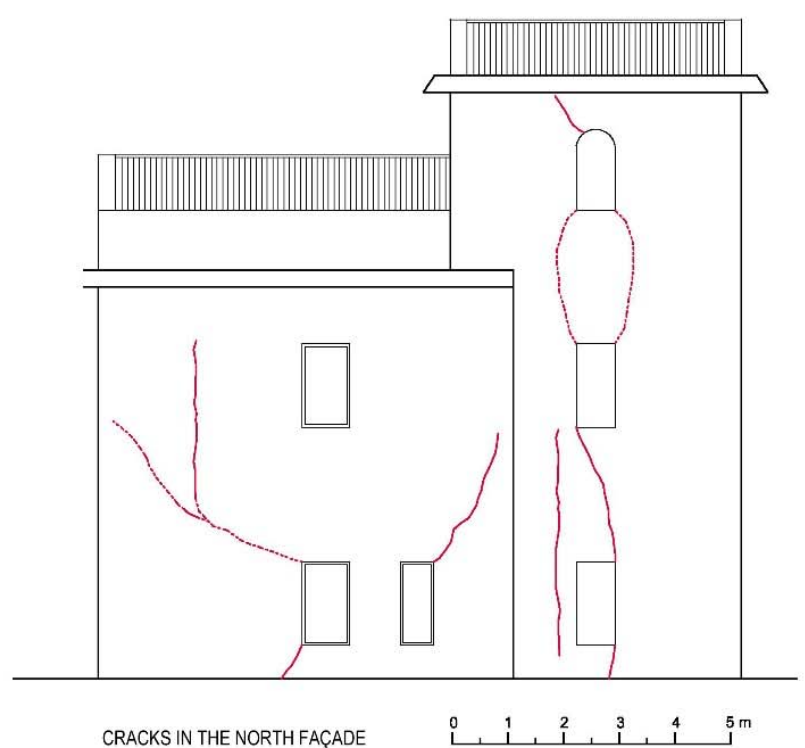

Figure 6. Maps of cracks in the east and north façades of the building.

Different tests were performed during the preliminary inspection process in an attempt to characterize the soil that was supporting the foundations of the building. The results revealed a high expansion rate (Seco et al. 2011). This showed that the soil was experiencing great changes in volume, indicating variations in its water content. These volume changes were producing movement of the foundations, which explained the seriousness of the damage to the building.

Once the expansion of the soil had been diagnosed, corrective measures could be applied to prevent further evolution of the pathological process. Ideally, these would include reinforcement of the foundations of the entire building, but since the budget could not accommodate the required expense, it was necessary to determine the floor areas where the greatest soil and foundation movements were concentrated. Such an analysis made it possible to design and choose specific measures to reduce the appearance, speed and severity of damage (Dulácska 1992). 
After some time, another inspection of the building was performed to determine the evolution of the movements and evaluate the significance of the damage. Levelling of different floors was carried out to highlight the locations of the greatest vertical deformation of the structure and to indicate those parts of the building where restoration work should be concentrated (Figure 7). In addition, the survey also focused on the thickness and crack density of the walls.
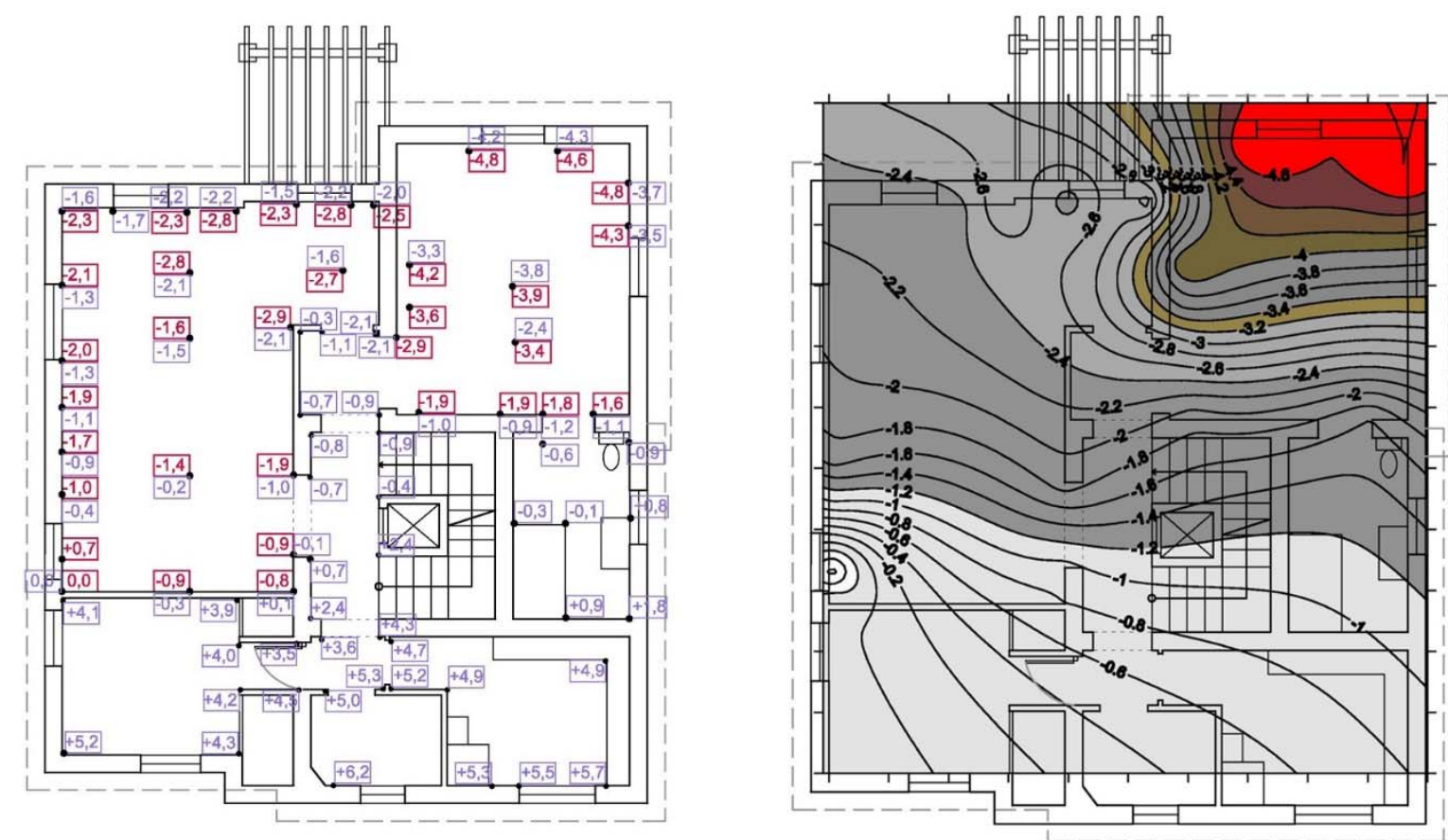

Figure 7. Left: Levelling nodes and the associated level values taken during in situ inspection. Right: Vertical deformation plan (contour map) made from the levelling nodes on the first floor of the building. The area of maximum vertical deformation (around $5 \mathrm{~cm}$ ) is shown in red.

As a result of the deformation and damage analysis, it was possible to conclude that the pathological symptoms came from settlement of the foundation due to soil movement. Analysis of the density and thickness of the cracks showed that a moderate damage category was appropriate (MacLeod \& Littlejohn 1974). Additionally, levelling and vertical deformation contour maps revealed a considerable difference between the floor areas on the opposite sides of the building. In order to reduce the damage caused to the building, a series of recommendations were provided, avoiding the selection of rehabilitation measures that would have required a much higher budget than 
that required for demolition and reconstruction work. These recommendations were focused on designspecific construction solutions to prevent the soil humidity changes caused by water from drainage or waste water pipes, especially in the areas exhibiting greater movement. In order to achieve this, it was decided to repair the existing sewage network to improve its water-tightness, involving the replacement of both existing brick manholes and sewer pipes (Nelson \& Miller 1997).

Thus, this work, linked to knowledge of the cause of the damage, could be focused on the area where the movement of the building was higher. In this way, final costs were reduced and, at the same time, it was possible to ensure that any future damage could be dealt with in an effective manner.

\subsection{SCHOOL CENTRE AT TURRE (ALMERÍA)}

Barely one month after construction work was finished in 2008, damage such as cracks on façades and columns began to appear in this building complex. This damage generally extended over both interior and exterior walls. Monitoring during the following three years revealed that the quantity, density and thickness of the cracking were progressively increasing, indicating an active deterioration process (Jaramillo-Morilla \& Huete-Fuertes 2011).

A complete inspection of the building was planned, which included tests to characterize the underlying soil together with a complete data collection scheme to provide an accurate representation of the extent of building damage (Kennie \& Petrie 1990). In addition, a ground-floor levelling of the building complex was performed in order to determine possible structural movement. Vertical deformation maps of the ground-floor slab of the two main buildings ( $A$ and $B$ ) were obtained using the previously described methodology (Figure 8). 


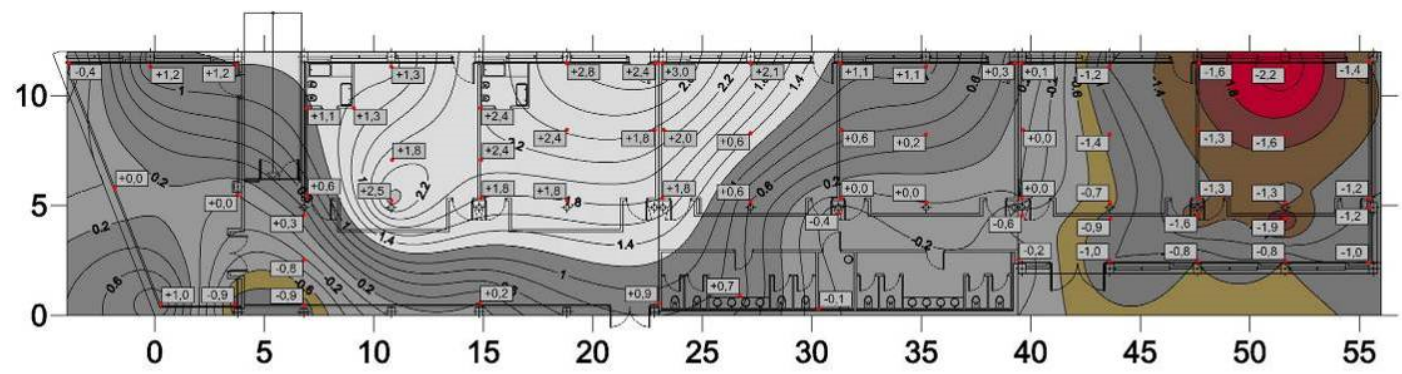

"A" BUILDING

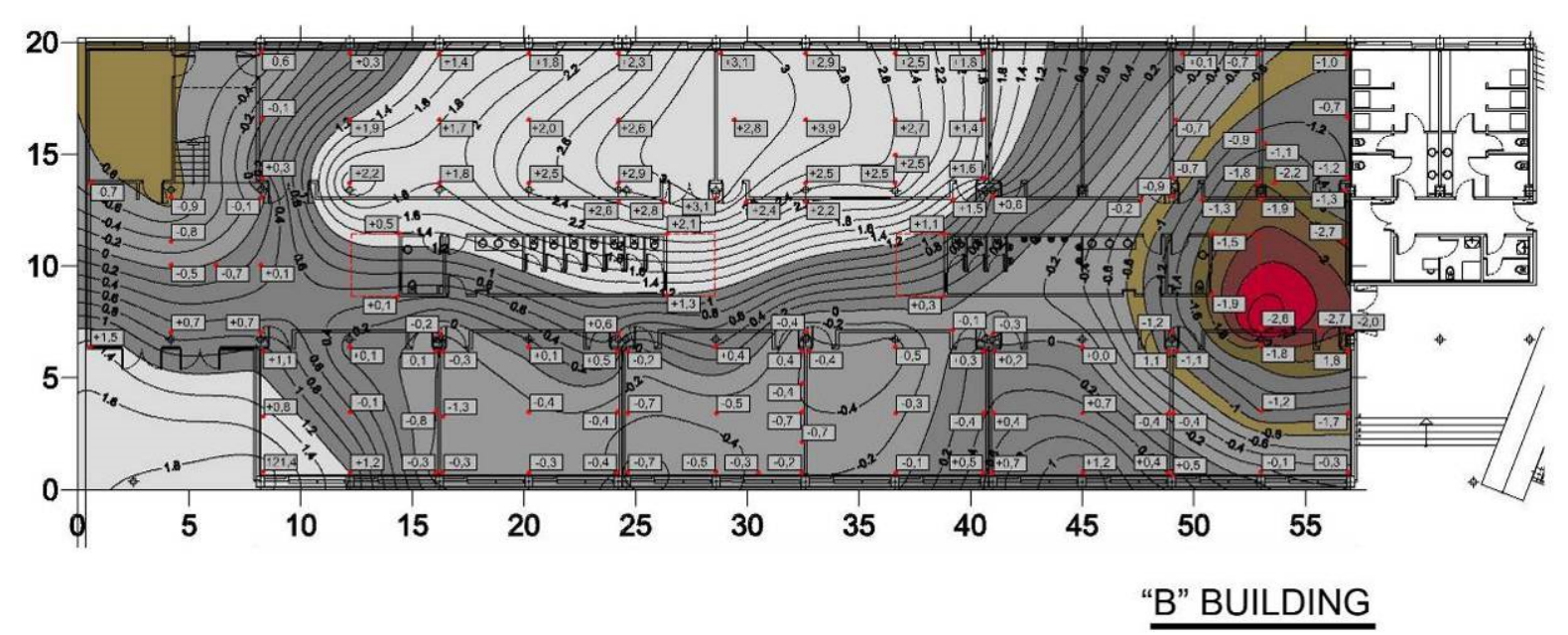

Figure 8. Ground-floor vertical deformation maps (contour maps) of the buildings forming the school complex. The areas with greatest movement are shown in red.

These maps clearly show those areas that suffered the greatest vertical movements (red) and, in contrast, those where this displacement was less than $1.0 \mathrm{~mm}$ (white). From these maps, 3D deformation sketches were generated (Figure 9).
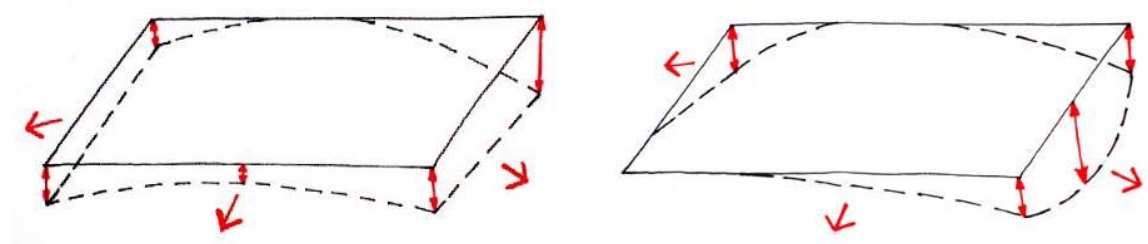

Figure 9. Sketches of deformation of the ground-floor slabs in buildings A and B produced from vertical deformation maps.

The results show that building $A$ had subsided on its opposite sides, with differences of $3.9 \mathrm{~cm}$ in the southwest façade and $5.2 \mathrm{~cm}$ in the northeast façade with respect to the geometric centre of the floor.

Building B had also settled on its opposite sides, with the differences in this case being $4.0 \mathrm{~cm}$ 
(southeast façade) and $6.6 \mathrm{~cm}$ (northwest façade). From this analysis, it was concluded that the building pathology was the result of differential settlement of the foundations. To determine the causes of this settlement, an analysis of the topographic plot levels was carried out, comparing the initial and final contour maps. The analysis revealed that the main reason for the settlement was insufficient compaction of the infill soil. This analysis also made it possible to dismiss other hypotheses that had initially been considered, such as expansion of clay in the soil (Potts \& Higgins 2004).

The restoration proposal for recovering stable and habitable conditions was divided into three main phases to correct the problems that had been found:

a) Reinforcement of the foundations.

b) Restoration of the cracking and loosening of facing on the interior and exterior walls.

c) Improvements in the structural conditions of columns.

\subsection{SAN JUAN DE DIOS HOSPITAL (MALAGA)}

After construction of this health centre was completed in 2009, and despite a detailed ground survey having been carried out, damage started to appear. This was revealed as cracks and subsidence of the exterior area of the building complex (Figure 10). These especially affected the perimeter road around the building and the exterior courtyard (Jaramillo-Morilla 2014).
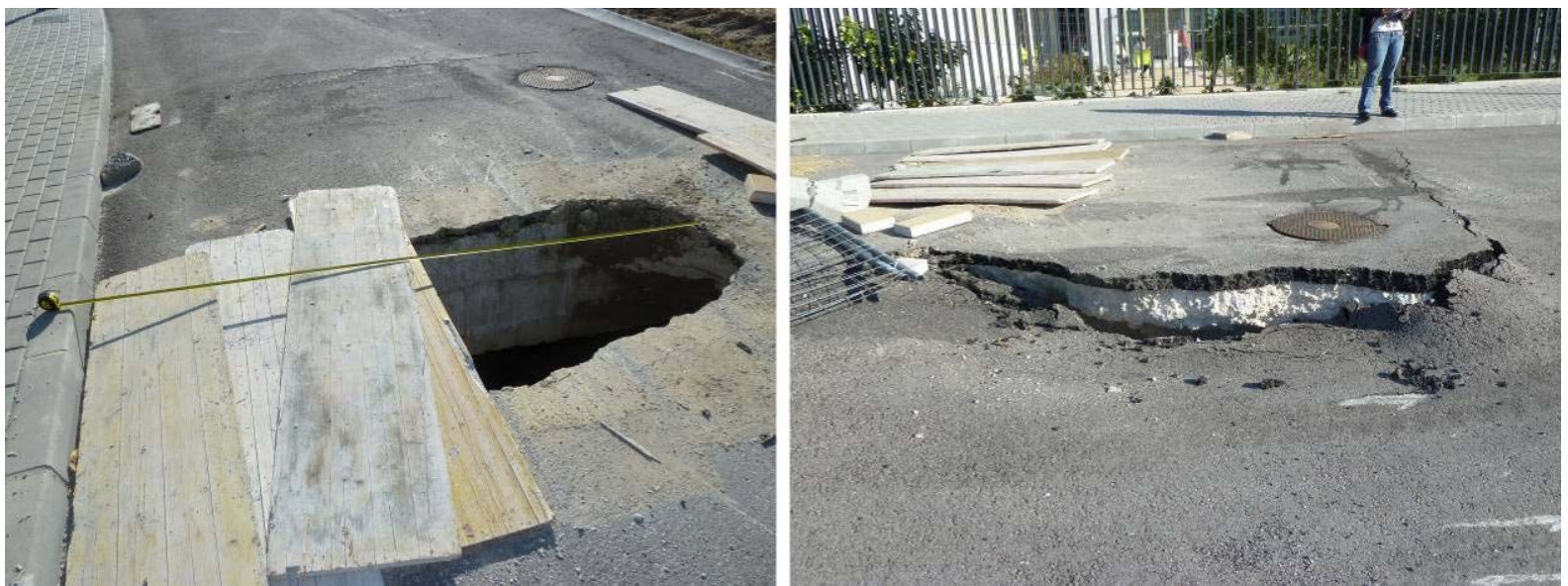

Figure 10. Damage arising from soil subsidence in the exterior area around the building and on the perimeter access roads. 
In 2013, visits were made to check the state of the building, as a key part of the analysis process before diagnosis of the pathologies. During these visits, a thorough compilation of the existing damage and a levelling were performed in order to determine the relative movements in the exterior area (Figure 11). The damage was concentrated around the façade and the perimeter road in the northeast, essentially shown by sinkage of the pavement surface by up to $30 \mathrm{~cm}$ and by openings of around $90 \mathrm{~cm}$ diameter. Evolution of the damage was confirmed during following visits, indicating that it had not remained constant, but rather had increased towards the edge of the road next to the slope. In addition, soil movement was shown to have affected the main sewer, causing water to leak and to flow into the soil. Geotechnical testing was conducted to complement the inspection in order to identify and characterize the soil, including dynamic penetration super-heavy (DPSH) tests, boreholes and pits (Noy \& Douglas 2005). Also, both unaltered and altered soil samples were extracted for later analysis in the laboratory.
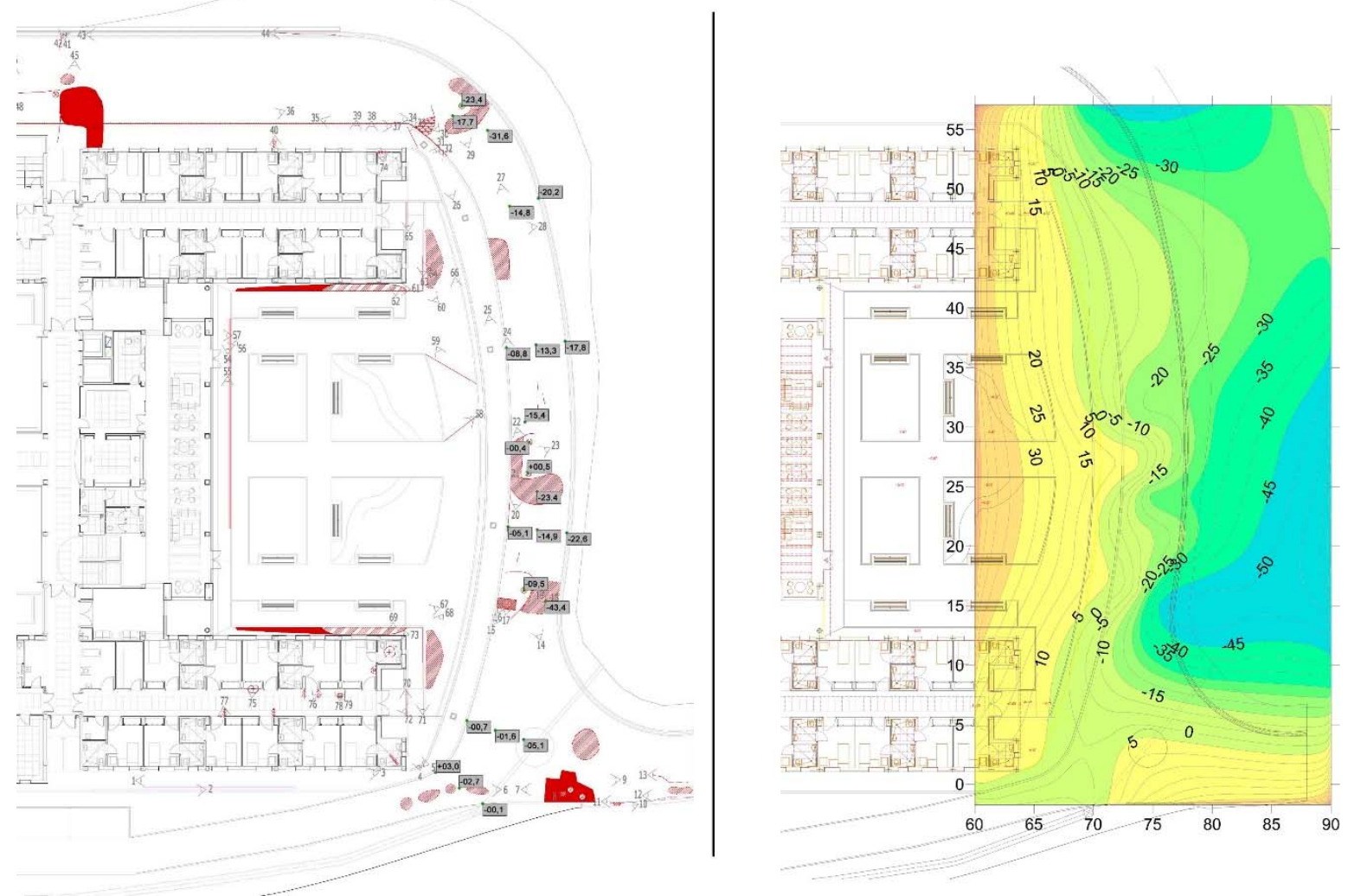

Figure 11. Left: Damage plan showing levelling results. Right: Vertical deformation of the exterior area obtained from levelling results. The lowest levels are shown in blue. 
A topographic study carried out on the building area showed that damage appeared over an area with 4.5 m-thick infill soil placed over the existing surface. However, it also revealed that an infill layer existed on the original soil before the building process commenced. Its thickness was about $3.0 \mathrm{~m}$, consequently increasing the total thickness of unconsolidated infill soil.

During the diagnostic process, the data acquired from the geotechnical soil characterization tests, the contour map showing the vertical deformation of the area and profiles obtained using groundpenetrating radar were all analysed. On the one hand, the laboratory tests on the infill soil indicated that their properties were satisfactory, so the problem did not arise from poor quality of the soil but rather from its subsequent treatment. Soil compaction was adequate only for the first metre depth, revealing that errors had occurred during the construction work and its supervision (Abramov 2008). Accordingly, it appeared that the subsidence problem was due to inadequate soil compaction during ground improvement. The subsidence was made worse by the flow through the soil of water coming from the broken sewer, and this in turn was a result of both the sewer and manholes being placed directly over the infill soil. Both the magnitude and speed of settlement and vertical deformation (subsidence) were increased by the action of this flowing water on the soil (Crilly 2001).

Based on this diagnosis, a technique to reinforce the foundations was proposed as a solution: IRS (injection, repetition and selection). This method guaranteed compaction of the infill soil and thereby the global stability of the building complex. It generated a rigid support sufficient for both the perimeter path and the building foundations (Hussin 2006).

\subsection{SANTO DOMINGO CHURCH IN SANTIAGO (CHILE)}

The current Santo Domingo church was built at the beginning of the nineteenth century over the ruins of three preceding churches that had to be demolished after damage by different earthquakes. In 2002, work to build a three-basement parking structure in the historic centre of Santiago de Chile was performed only a few metres away from the eastern façade of the church. As a result, damage to the 
church wall necessitated the adoption of repair measures and structural reinforcement, including the construction of a concrete floor to brace the base of all the columns of the building.

The appearance of cracks on the pavement during 2015 led to a technical inspection of the building being carried out to verify its structural safety. During this process, in addition to tests and structural checks, a church floor levelling was performed with the goal of determining any deformation or structural settlement. The results of this levelling are shown in Figure 12.
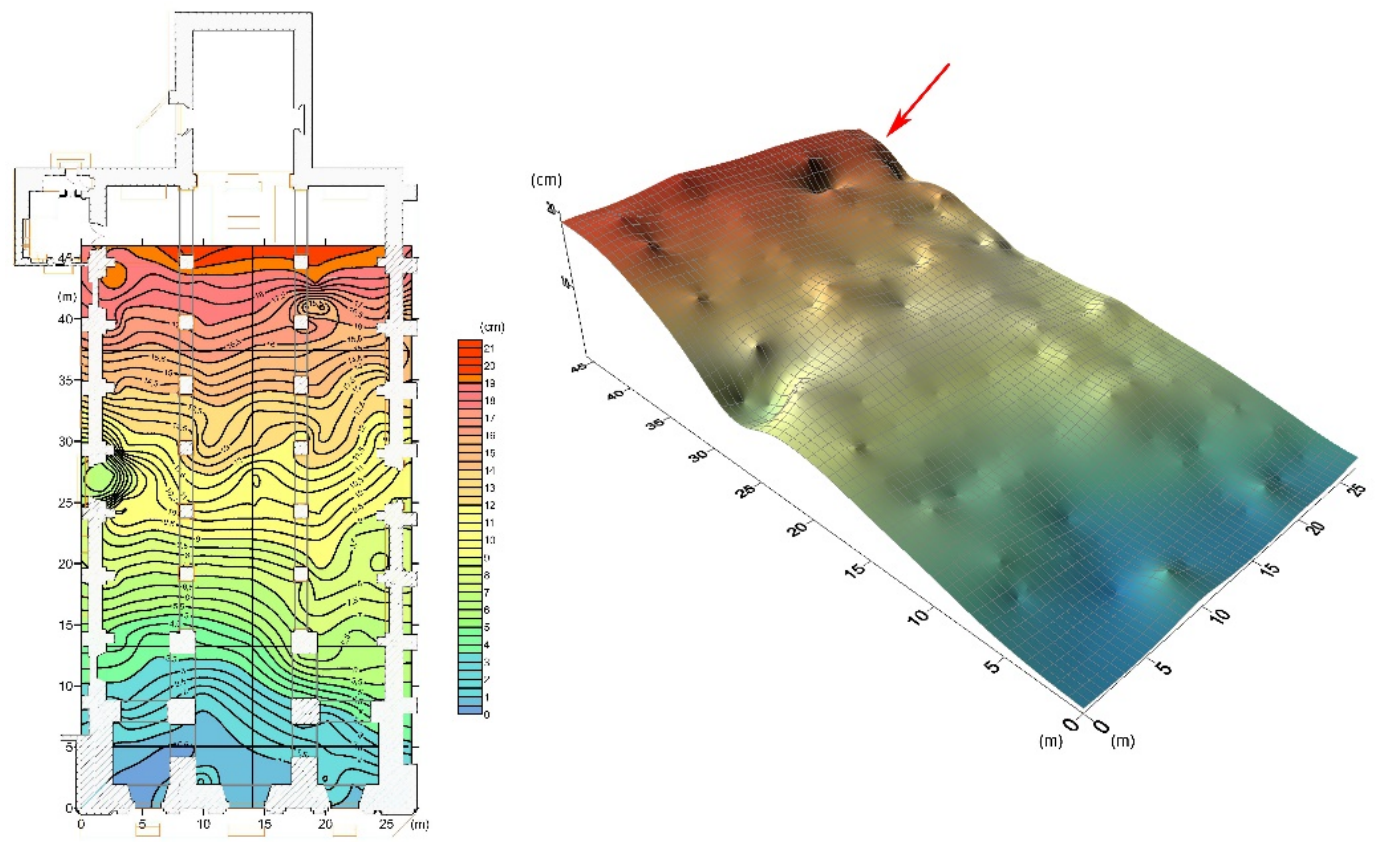

Figure 12. Left: Contour map located over the plan of the church. Right: 3D surface map of the pavement level. The lowest levels are shown in blue.

Preliminary results show the original floor slope towards the altar creating a theatrical effect to provide a better view during worship. In addition to this, there are valleys and a downward slope in the lateral access areas to allow drainage of water. In addition, it is possible to observe in the upper right corner a dip (shown with a red arrow in Figure 12) that implies a subsidence in both the bracing slab and the church wall.

This example illustrates the usefulness of the proposed method for the inspection of heritage buildings. 


\section{CONCLUSIONS}

Surveys related to the maintenance and preservation of existing buildings are among the most demanding tasks for surveyors. It is necessary to use in situ techniques (preferably non-destructive) that ensure a satisfactory determination of the state of a building, reducing margins of uncertainty. This work has to be based on a set of techniques and tools that provide the surveyor with specific and accurate information. A high-quality analysis and diagnostic process makes it possible to propose the most appropriate measures to solve problems, as well as optimizing both costs and working budget. As part of this procedure, the methodology described in this paper allows an estimation of the vertical deformation of structures and construction elements. Based on data obtained from levelling during inspection, a 2D contour map or 3D surface map of such deformation can be produced. This information simplifies and facilitates outcome analysis by expert practitioners and consequently allows a correct diagnosis to be reached. Furthermore, such graphics facilitate understanding of technical and specialized information about the causes of building pathology by non-specialist staff such as lawyers. For example, better decisions can then be made when determining the responsible parties in a legal dispute.

The simplicity of this methodology and its low cost (as a result of the lack of any need for complex equipment), combined with the excellent quality of the results obtained, confirms its validity as an essential approach to the analysis and diagnosis of the causes of building pathology. Its utility is supported by the results obtained in the different case studies presented here. This procedure, as a complement to other conventional surveys and commonly used inspection techniques, provides complete information about the state of a building, leading to better understanding of the causes of building damage and therefore makes diagnosis easier.

\section{REFERENCES}

Abramov, N.N., 2008. Use of geophysical methods to assess the quality of compaction of fill 
soils. Power Technology and Engineering, 42(3), pp.133-136.

Alkan, R.M. \& Karsidag, G., 2012. Analysis of the accuracy of terrestrial laser scanning measurements. In FIG Working Week 2012. Rome, Italy: International Federation of Surveyors (FIG), p. 16.

Anon, 2012. Surfer: Contouring and 3D Surface Mapping for Scientists and Engineers. , p.60.

Avilés, F., 2011. Sobre el deber de conservación de los edificios. Lesiones más frecuentes derivadas de la falta de conservación en la edificación y su alcance económico. Afección a la seguridad y salubridad. In Cartagena, Murcia: Colegio Oficial de Arquitectos de Murcia (COAMU), pp. 1-12.

Berenyi, A., Lovas, T. \& Arpad Barsi, 2010. Terrestrial laser scanning in engineering survey: analysis and application examples. In ASPRS 2010 Annual Conference. San Diego, California: American Society for Photogrammetry and Remote Sensing, p. 8.

Bourges, M., Mari, J.-L. \& Jeannée, N., 2012. A practical review of geostatistical processing applied to geophysical data: methods and applications. Geophysical Prospecting, 60(3), pp.400-412.

Camarda, M. et al., 2010. Health monitoring of complex structure using TLS and photogrammetry. In ISPRS. Proceedings of the International Archives of the Photogrammetry, Remote Sensing and Spatial Information Sciences. Newcastle upon Tyne, UK: International Society for Photogrammetric and Remote Sensing (ISPRS).

Clarke, J.A. \& Laefer, D.F., 2013. Systematic Approach for Large-Scale, Rapid, Dilapidation Surveys of Historic Masonry Buildings. International Journal of Architectural Heritage, 8(2), pp.290-310.

Cosarca, C., Jocea, A. \& Savu, A., 2009. Analysis of error sources in Terrestrial Laser Scanning. RevCAD - Journal of Geodesy and Cadastre, 9, pp.115-124. 
Crilly, M., 2001. Analysis of a database of subsidence damage. Structural Survey, 19(1), pp.7-15.

Cuartero, A. et al., 2010. Error analysis of terrestrial laser scanning data by means of spherical statistics and 3D graphs. Sensors (Basel, Switzerland), 10(11), pp.10128-45.

Dulácska, E., 1992. Soil settlement effects on buildings 1st ed., Amsterdam, Holland: Elsevier.

Dumalski, A., 2011. Evaluation of possible application of terrestrial laser scanner scanstation in vertical displacement measurements. Technical Sciences, 14(1), pp.33-43.

Durán-Dominguez, G., Felicisimo, A. \& Polo, M.-E., 2014. 3D study of cultural heritage for conservation. Reliability of the portable 3D laser scanners. In International Congress on Science and Technology for the Conservation of Cultural Heritage. Seville, Spain.

El-Tokhey, M.E. et al., 2013. Accuracy assessment of laser scanner in measuring and monitoring deformations of structures. World Applied Sciences Journal, 26(2), pp.144151.

Forcada, N. et al., 2014. Assessment of construction defects in residential buildings in Spain. Building Research \& Information, 42(5), pp.629-640.

Fregonese, L. et al., 2013. Surveying and Monitoring for Vulnerability Assessment of an Ancient Building. Sensors, pp.9747-9773.

Grussenmeyer, P. et al., 2008. Comparison methods of terrestrial laser scanning, photogrammetry and tacheometry data for recording of cultural heritage buildings. In The International Archives of the Photogrammetry, Remote Sensing and Spatial Information Sciences. Beijing, China: International Society for Photogrammetric and Remote Sensing (ISPRS), pp. 213-218.

Gubellini, A., Lombardini, G. \& Russo, P., 1986. Application of high precision levelling and photogrammetry to the detection of the movements of an architectonic complex 
produced by subsidence in the town of Bologna. In IAHS. Proc. 3rd International Symposium on Land Subsidence. Venice, Italy: Wallingford, pp. 257-267.

Guerra-Santin, O. \& Tweed Aidan, C., 2015. In-use monitoring of buildings: An overview and classification of evaluation methods. Energy and Buildings, 86, pp.176-189.

Harris, S.Y., 2011. Building Pathology: Deterioration, Diagnostics, and Intervention, Portland, USA: Wiley \& Sons.

Hussin, J.D.., 2006. CRCnetBASE - Methods of Soft Ground Improvement. In M. Gunaratne, ed. The Foundation Engineering Handbook. CRC Press, pp. 529-566.

Ioannidis, C. \& Georgopoulos, A., 2007. Innovative Techniques for the Acquisition and Processing of Multisource Data for the Geometric Documentation of Monuments. International Journal of Architectural Computing, 5(2), pp.180-197.

Jaramillo-Morilla, A., 2014. Informe sobre los daños en la urbanización exterior del Hospital San Juan de Dios en Málaga, Seville, Spain.

Jaramillo-Morilla, A. \& Huete-Fuertes, R., 2011. Dictamen técnico sobre las lesiones identificadas en los edificios del Centro Escolar de Infantil y Primaria (CEIP) “María Cacho Castrillo” Turre (Almería), Seville, Spain.

Jaramillo-Morilla, A. \& Pérez-Murillo, A., 2011. Informe preliminar sobre los daños en una vivienda unifamiliar aislada en la c/Perú $n^{o} 1$ (Sevilla), Seville, Spain.

Josephson, P.-E. \& Hammarlund, Y., 1999. The causes and costs of defects in construction. Automation in Construction, 8(6), pp.681-687.

Kennie, T.J.M. \& Petrie, G., 1990. Engineering Surveying Technology 1st ed., Oxon, UK: Taylor \& Francis.

Ma, Z. et al., 2012. Existing building retrofits: Methodology and state-of-the-art. Energy and Buildings, 55, pp.889-902. 
MacLeod, I.A. \& Littlejohn, G.S., 1974. Discussion on Session 5. In: Conf. Settlement of Structures. In The Skempton Conference. Cambridge, UK: Pentech Press, pp. 792-795. MEDID, 2008. Láser multilínea automático compac 5104.

Moropoulou, A. et al., 2013. Non-destructive techniques as a tool for the protection of built cultural heritage. Construction and Building Materials, 48, pp.1222-1239.

Nelson, J. \& Miller, D.J., 1997. Expansive Soils: Problems and Practice in Foundation and Pavement Engineering 1st ed., New York, USA: Wiley.

Noy, E. \& Douglas, J., 2005. Building Surveys and Reports 4th ed., Sussex, UK: Blackwell Publishing.

Patias, P. et al., 2006. A proposed low-cost system for 3D archaeological documentation. In M. Ioannides et al., eds. 7th International Symposium on Virtual Reality, Archaeology and Cultural Heritage (VAST). Nicosia, Cyprus: The Eurographics Association, pp. 129134.

Polo, M.-E. et al., 2012. Estimating the uncertainty of Terrestrial Laser Scanner measurements. IEEE transactions on geoscience and remote sensing, p.5.

Potts, D.M. \& Higgins, K.G., 2004. Advances in Geotechnical Engineering: The Skempton Conference, Volume 1 1st ed., London, UK: Thomas Telford.

Reynolds, J.M., 2011. An Introduction to Applied and Environmental Geophysics 2nd ed., Chichester, West Sussex: John Wiley \& Sons.

Russo, P., 1980. Results of recent levellings in the region of Modena. In 3rd International Symposium on Land Subsidence. Venice, Italy: Wallingford, pp. 213-224.

Seco, A. et al., 2011. Stabilization of expansive soils for use in construction. Applied Clay Science, 51(3), pp.348-352. 
Smith, H. \& Ferris, J.B., 2010. Techniques for averting and correcting errors in 3D terrain topology measurements. Journal of Terramechanics, 47(4), pp.219-225.

Upson, C. et al., 1989. The application visualization system: a computational environment for scientific visualization. IEEE Computer Graphics and Applications, 9(4), pp.30-42.

Watt, D., 2008. Building Pathology: Principles and Practice, 2nd Edition - David Watt 2nd ed., Oxford, UK: Wiley-Blackwell.

Di Yajing \& Bai Chengjun, 2011. Application scope of the Terrestrial Laser Scanner in measured survey on architectural heritages. In 2011 International Conference on Electric Technology and Civil Engineering (ICETCE). Lushan: IEEE, pp. 2954-2957.

Yan, C.-S. et al., 2004. Twelve different interpolation methods: a case study of Surfer 8.0. In O. Altan, ed. XXth ISPRS Congress. Istambul, Turkey: International Society for Photogrammetric and Remote Sensing, pp. 778-785.

Zotov, M. V., 2003. Leveling of a Multistory Building Subject to Seismic Effects. Soil Mechanics and Foundation Engineering, 40(4), pp.141-145. 